\title{
JUSTICIA EN CLAVE FEMINISTA Y COMUNITARIA: DES[BORDES] FRENTE A LAS INSTITUCIONALIDADES PATRIARCALES
}

\author{
FEMINIST AND COMMUNITY JUSTICE: DIS(EDGES) AGAINST \\ PATRIARCHAL INSTITUTIONALIZATIONS \\ (iD) María Eugenia Gastiazoro ${ }^{*}$, (i) Candelaria Sgró Ruata ${ }^{1}$, (iD Paola Bonavitta ${ }^{1}$ \\ eugegastiazoro@gmail.com; candelariasgro@yahoo.com; paola.bonavitta@gmail.com \\ ${ }^{1}$ Universidad Nacional de Córdova, Córdova, Argentina
}

*Correspondencia: María Eugenia Gastiazoro. Email: eugegastiazoro@gmail.com

Recibido: 09.08.21 | Aprobado: 29.08.21

\section{RESUMEN}

Este trabajo aborda tensiones y fortalezas de construir una justicia en clave feminista desde experiencias en Argentina y Latinoamerica. Desde una metodología ensayística, se discute las posibilidades amplias de la justicia y los aportes de los feminismos ante las violencias contra mujeres y cuerpos feminizados, en orden a polemizar las respuestas reducidas a dinámicas de punitivismo/culpa/castigo. Analizamos tensiones entre la cultura legal estatal frente a la popular a partir de la Sentencia del Tribunal Ético Popular Feminista del Abya Yala (2018). Luego, exploramos los límites y las contradicciones de plantear la solución de conflictos sociales desde la lengua penal; utilizamos como ejemplo el debate parlamentario sobre Interrupción Voluntaria del Embarazo en el cual se discutió su (des)penalización y legalización con la participación de la sociedad civil Argentina. Finalmente, recurrimos a los feminismos comunitarios, para rescatar aspectos de una justicia colectiva restauradora de lazos sociales, no centrada en lo sancionatorio.

Palabras clave: Justicia feminista, derechos, patriarcado, género, decolonial.

\section{ABSTRACT}

This paper addresses the tensions and strengths of building feminist justice in the Argentine and Latin American context. From an essayistic methodology, it discusses the broad possibilities of justice and the contributions of feminisms regarding violence against women and feminized bodies, which polemicizes the responses reduced to punitivism/ blame/punishment dynamics. First, we analyze the tensions between state versus popular legal culture based on the Feminist People's Ethical Tribunal Judgment (2018). Then, we address the limits and contradictions of approaching the solution of social conflicts from the criminal language; We use as an example the parliamentary debate on the Voluntary Interruption of Pregnancy in which its (de)criminalization and legalization was discussed in a scenario of civil society participation in Argentina. Finally, we turn to community feminisms, to rescue aspects of a collective justice that restores social ties, not centered on punishment.

Keywords: Feminist justice, rights, patriarchy, gender, decolonial. 


\section{INTRODUCCIÓN}

En Argentina, las renovadas exigencias de una justicia feminista vuelven a colocar el tema en agenda respecto de qué implica esta demanda dentro del amplio abanico de posibilidades, frente al reduccionismo de las soluciones punitivas y securitistas y su afinidad con un orden neoliberal (Arnés, 2017). El movimiento \#Niunamenos (NUM) en el año 2017 se opuso a la demagogia punitiva ante la indignación social por el crimen de Micaela (López, 2019). Daich y Varela (2020) sostienen que la encrucijada de los feminismos y el poder punitivo: “implica desacoplar derecho y justicia para alimentar una imaginación feminista capaz de producir claves propias de formulación e inteligibilidad de los problemas" (p. 19). A principios del año 2021, frente a la concurrencia de femicidios, la consigna de reforma judicial feminista fue reavivada en distintos espacios tanto de militancia, partidarios como académicos, con un principio transversal en las discusiones ¿cómo abordar los conflictos por fuera de la lente punitivista ligada al sistema heteropatriarcal, racista y clasista? las respuestas no tienen recetas, y es por eso que en el presente artículo proponemos esbozar tensiones y encuentros en el desarrollo de una justicia feminista desde procesos regulatorios y emancipatorios (Santos, 2009). Es decir, poner en juego las dimensiones de justicia(s), género(s), feminismo(s), derechos y sistemas de justicia desde una mirada crítica de la colonialidad. Esto implica reconocer y dialogar con los saberes situados territorialmente para evitar la generación y reproducción de lógicas colonizadas y colonizadoras y desandar los patrones del saber-poder del mundo moderno. Significa abrir preguntas y horizontes más allá de las respuestas punitivismo/culpa/ castigo frente a las violencias contra las mujeres y cuerpos feminizados. Escudriñar en los pluralismos jurídicos y en las maneras de entender y hacer el derecho y la justicia -desde abajo y desde arriba- como en otros órdenes que no sean aquellos identificados solo con el derecho positivo estatal moderno. En este ensayo, presentamos la tensión entre los términos de cultura legal estatal frente a la cultura popular (Salvatore, 2010) a partir de la Sentencia del Tribunal Ético Popular Feminista (2018). Luego, esbozamos los límites y contradicciones de plantear la solución de conflictos sociales en la lengua de lo penal (Cano, 2016), en este marco profundizamos en el debate parlamentario en el Congreso de la Nación (2018) sobre la Interrupción Voluntaria del Embarazo (IVE) en el cual se discutió la (des)penalización y legalización del aborto en un escenario de movilización y participación de diferentes actores de la sociedad civil. Por último, recurrimos a la mirada de los feminismos comunitarios, los cuales apuntan a la resolución de conflictos, desde la justicia construida colectivamente y restauradora de lazos sociales.

\section{"La justicia feminista no es una justicia del castigo, pero tampoco es una justicia de la impunidad" -Tribunal Ético Popular Feminista"}

Los sistemas de justicia y órdenes jurídicos son parte de los dispositivos de homogeneización. En este sentido, Segato (2007) reflexiona sobre la colonialidad de la justicia en América Latina, donde encuentra que la selectividad de la justicia penal está racializada, en conexión a la historia de nuestro continente como de la construcción de los Estados bajo el ideal mestizo y el crisol de razas: 
La construcción permanente de la raza obedece a la finalidad de la subyugación, la subalternización, y la expropiación. Es del orden racial de donde emana el orden carcelario, pero éste lo retroalimenta. Y el orden racial es el orden colonial. Esto quiere decir que el etiquetamiento no ocurre en la ejecución policial ni en el procedimiento de sentenciar. La acción policial y la sentencia refuerzan y reproducen el etiquetamiento preexistente de la raza (p. 150).

La subalternización también recae sobre las mujeres y disidencias en intersección con las dimensiones de raza y clase social (Viveros Vigoya, 2016). El imaginario jurídico de "la mujer" de la América colonial se construyó sobre los criterios que históricamente clasificaron a las mujeres occidentales, sostenida en una "naturaleza femenina" que significó la imposición del control de los cuerpos (Vasallo, 2007). Las instituciones como el sistema judicial y la cárcel tienen una tarea central en la dimensión realizativa del género en tanto que legitiman determinadas conductas y procederes y penalizan otros, en base a los postulados del patriarcado heteronormativo (Deangeli, Gastiazoro y Sánchez, 2019).

Durante el mes de junio de 2018 se reunió en Buenos Aires, Argentina, el Tribunal Ético Popular Feminista, que dictó sentencia para concluir con el primer ciclo del Juicio a la Justicia Patriarcal, iniciado en Resistencia, Chaco, en octubre de 2017, en el marco del $32^{\circ}$ Encuentro Nacional de Mujeres -recientemente denominado Plurinacional de Mujeres, Lesbianas, Travestis, Trans y No Binaries-. Este tribunal, se construyó como un espacio que tuvo por objetivo no sólo denunciar a la Justicia patriarcal institucional, sino también instalar una justicia de cuidado y sanación para las víctimas (directas, familiares y/o amigas), por medio de un proceso donde se la resignificó como "compañera". A través de la escucha y puesta en valor de la palabra de quienes fueron maltratadas, invisibilizadas o revictimizadas en los tribunales y limitadas en el acceso a la justicia se logró inscribir y descifrar desde una mirada colectiva situaciones vividas como individuales. De esta manera, las reuniones por medio de audiencias fueron para quienes participaron: un modo de encuentro político pedagógico en el que pudimos escucharnos, sentirnos, acompañarnos, y pensar juntas cómo defendernos frente a las múltiples violencias del patriarcado colonial y capitalista, abriendo diálogos e intercambios para imaginar y pensar caminos hacia una justicia feminista, antirracista, originaria, comunitaria y popular (Sentencia Tribunal Ético Popular Feminista, 2018, p.1).

Esta Sentencia permite pensar con y contra la justicia institucional y burocrática, no sólo para juzgar su accionar y omisiones, sino también para construir otra justicia. Es decir, mujeres y cuerpos feminizados se instalan frente a este tipo de Justicia estatal, para imaginar una justicia feminista, antirracista, originaria, comunitaria y popular. Las audiencias y sesiones del Tribunal pusieron en cuestión las violencias institucionales para disputar sentidos desde afuera e interpelar a la justicia patriarcal estatal; es esta la dimensión política que constantemente da vida a los derechos de las mujeres y cuerpos feminizados, e impide que funcione como mera tecnología de género (Smart, 2000) reproductora de desigualdades. Esto implica vitalizar el derecho como ámbito de disputa de sentidos tanto desde dentro de los sistemas estatales como en los entramados sociales de nuestras comunidades, organizaciones y sociedades (Sgró y Gastiazoro, 2018). 
El Tribunal Ético Feminista desborda lo institucional y académico, para pensarse desde afuera de esa Estatalidad que sujeta a los cuerpos. Si bien, persiste la reclamación al Estado como garante de acceso a la justicia, también se promueve una forma de pensar y resolver en comunidad de redes y encuentros aquello que en la institucionalidad de la Justicia no puede o no quiere mirar; se pretende generar dinámicas desde abajo y entre mujeres (cis, trans, lesbianas, etc.), que implican su cuestionamiento y reconstrucción:

(...) Abrimos así un camino hacia la construcción de otra justicia, donde nuestros cuerpos, nuestras vidas, nuestras palabras, nuestros deseos, nuestros territorios, nuestros pueblos, sean protagonistas, y encontremos los modos de defendernos, sanarnos, y reivindicar nuestro derecho a rebelarnos ante todas las opresiones y a crear nuevos modos de vivir, de sentir, desde nuestras cosmovisiones, proyectos y formas de ver la vida (Sentencia Tribunal Ético Popular Feminista, 2018, p.1).

Sobre la tensión entre los términos cultura legal estatal frente a la cultura popular, planteado por Salvatore (2010), interpretamos, que este tipo de demandas de una justicia feminista implica tensionar la cultura legal estatal, tanto a partir de su cuestionamiento como desde la creación de dinámicas políticas de justicia en términos éticos, cooperativos y nutrientes para quienes han participado de estos encuentros. Esto lleva a trabajar sobre el concepto de cultura popular, en términos de las interpelaciones que desde afuera se realiza a la justicia institucional, y que de algún modo complejizan con sus resonancias aquel ámbito. Es decir, de acuerdo con Salvatore (2010), la cultura legal estatal es la cultura del orden institucional estatal, por medio de la cual se construyen categorías que clasifican y encasillan, implicando una subalternización de determinados sujetos sociales, de acuerdo con desigualdades de clase, género, raza, educación, entre otras.

Esto significa que: "legislación, jurisprudencia, doctrina legal y práctica judicial y policial constituyen un vasto espacio discursivo donde se generan y reproducen las nociones dominantes sobre orden social, delito, desviación y pena" (Salvatore, 2010, p. 41). Por otro lado, quienes están en posiciones subalternas generan críticas que significan poner en cuestión el discurso experto de la administración de justicia, lo que configura la cultura popular frente a la estatal. De allí la importancia de los "fragmentos de enunciación subalterna que aparecen en los archivos del Estado" (Salvatore, 2010, p. 20). En el caso de estudio, se observa que la puesta en cuestión del discurso dominante del poder judicial surge por fuera del orden institucional, para cuestionar -en el marco del Encuentro Nacional Plurinacional de Mujeres, Lesbianas, Travestis, Trans y No Binaries- las violencias y limitaciones al acceso a la justicia en casos donde por su modo de intervención u omisión se hace responsable a los poderes judiciales. Esto nos lleva a reconceptualizar el término de Salvatore (2010) para abordar la cultura legal popular en un sentido amplio y no reducido al espacio estatal centrado solo en archivos del Estado, que interpela la subalternización que se produce ante la legitimación de violencias y crímenes cometidos por el poder patriarcal, machista y clasista de acuerdo a los casos presentados y correspondientes a distintas jurisdicciones de Argentina como de otros países de Latinoamérica (Sentencia Tribunal Ético Popular Feminista, 2018).

La justicia y la lengua de lo penal: contradicciones de solicitar el poder punitivo del Estado en la resolución de conflictos 
Recurrir al sistema penal como modo de resolución de conflictos, -especialmente si nos centramos en las violencias contra las mujeres y poblaciones LGTTBQI+-, implica abordar las contradicciones y discusiones que conlleva el uso del poder punitivo del Estado. Tensiones que se revelan cuando las demandas hacia el Estado y los derechos exigidos por los movimientos sociales quedan limitadas a los términos punitivos lo que obtura nuestra imaginación política (Daich y Varela, 2020; Cano, 2020). El ensayo de Cano (2016) interpela en dos sentidos: por un lado, la masiva movilización del primer \#Niunamenos (NUM) del año 2015 se instaló como paradigma que visibilizó el disciplinamiento cisheteropatriarcal frente al paradigma del crimen pasional centrado en el modelo de arrebato de locura individual que justifica incluso la impunidad de estos crímenes. Sin embargo, no deja de entrever los límites y riesgos de la propagación del discurso jurídico penal del femicidio hacia ámbitos extrajurídicos, tanto hacia los medios de comunicación masiva como en las mismas demandas de los distintos movimientos sociales (incluidos movimientos feministas y LGTTBQI+). Su crítica de "la razón femicida", se enmarca en lo señalado por Pitch (2014): la perspectiva penal reduce el problema de la violencia de género(s) a dos categorías excluyentes: víctimas y victimarios; personaliza el problema; puntúa responsabilidades individuales; reduce las posiciones subjetivas a un esquema rígido, jerárquico y binario; estereotipa una imagen de mujer pasividad y víctima- y de varón -activo y victimario-. En este sentido, sostiene Cano (2016), este discurso femicida "acaba personalizando -y responsabilizando- a individuos particulares del ejercicio de la violencia cis-hetero-patriarcal que nos atraviesa -pasiva o activamente- a todos, y que requiere de nuestro trabajo personal y colectivo" (p.13). Esto indica las consecuencias limitativas de plantear desde la lengua de lo penal los conflictos sociales lo que lleva de alguna manera a confundir la justicia formal con la justicia social (Trebisacce, 2018).

Claramente, el planteo no significa que el sistema de justicia penal como tal no intervenga en los delitos correspondientes o no sea utilizado por las mujeres y personas LGTTBQI+ en sus demandas de protección. Sabemos que la justicia penal requiere ser renovada continuamente desde las teorías legales y perspectivas socio-jurídicas feministas y transfeministas para abordar sus conflictos, y en este sentido no replicar y sostener prácticas que avalan el cis-hetero-patriarcado como se mostró en casos que trascendieron públicamente en Argentina. La necesidad de que el Estado responda en casos de violencia, daños, abusos sexuales, es vital frente al ninguneo de las mujeres y corporalidades feminizadas; en este sentido, tanto los sistemas judiciales como las profesiones jurídicas son responsables frente a lo que Arduino (2018) denomina "impunidad selectiva" y "garantismo misógino" que recae sobre determinadas identidades sexo-genéricas atravesadas a su vez por condiciones sociales que intensifican las discriminaciones (pobres, marronas, indígenas, etc.).

Lerussi y Costa (2018) en su recorrido sobre los feminismos jurídicos en Argentina, se sitúan en la década de los ' 90 , -época signada en Argentina por políticas neoliberales y el subsiguiente incremento de la pobreza, tensionado con un discurso de consolidación del lenguaje de los derechos de la mano de los movimientos sociales (ya sea de mujeres y feminismos; derechos humanos; colectivos LGT'TBQI+ e internacionalización de los movimientos)-. En este marco, las autoras indican que se configuró la apropiación de la 
categoría género tomada del feminismo norteamericano por parte de los discursos académicos y del derecho en Latinoamérica (Lerussi y Costa, 2018). Esto significó discusiones en torno a cómo abordar su interrelación en la arena del derecho penal: ¿Un derecho penal de mínima o de máxima? Simplificado en dos corrientes: la abolicionista frente a la punitivista. En este sentido, como bien lo resumen las autoras, mientras que algunas perspectivas entienden que una justicia de género debe ser incorporada al enfoque de un derecho penal mínimo, otras rechazan de pleno una alianza entre un movimiento social de emancipación y el poder punitivo del Estado, ejercido de manera selectiva y discriminatoria por su propia estructura (Lemaitre, en Lerussi y costa, 2018, p.11).

En Argentina, los feminismos populares "hicieron estallar la diferenciación entre buenas y malas víctimas y, al mismo tiempo, pusieron en discusión la propia categoría de víctima” (López, 2019, p. 38); sostienen, a su vez, la necesidad de tramitar el miedo de una forma que no sea centrada en la seguridad de carácter individualista y punitivista (López, 2019). Es en este sentido que retomamos a Cano (2016) quien se pregunta sobre los límites y las potencias del discurso construido sobre la figura penal del femicidio al abordar el carácter productivo de la razón femicida: ¿Qué sucede cuando el abordaje de los conflictos se institucionaliza, pero encorsetado en lógicas cis-hetero patriarcales de opresión, violencia y reproducción de violencia? ¿Qué limitaciones tiene el avance de la denuncia feminista en el orden jurídico? ¿Cuáles son los límites y potencias del discurso construido penal al abordar el carácter productivo de la razón femicida? Es decir, si lo visibilizado en términos de femicidio queda circunscripto, como sugiere Trebisacce (2016), en una "matriz de inteligibilidad de las experiencias, resultado de una interpretación del funcionamiento de opresión de las mujeres, que anticipa las experiencias posibles de ser reconocidas como tales y las recorta de otras que no consiguen siquiera ser visualizadas" (p. 291).

\section{AMPLIAR DERECHOS, HORIZONTES E IMAGINACIONES POLÍTICAS}

Una de las formas de visibilizar las maneras en que el derecho se convierte en un campo de disputas, tanto por la transformación jurídica como de los sentidos y jerarquizaciones politizadas en lo público, es cuando un proyecto de ley sobre derechos sexuales y reproductivos (DSyR) logra ingresar al debate parlamentario. Es una instancia donde las disputas por lo (no) decible toman cuerpo y más allá de lo que la ley sanciona, en el debate público emerge aquello que busca (re)inscribirse como sancionable.

El 2018, en Argentina, es un ejemplo claro. Por primera vez, luego de numerosas presentaciones, la discusión sobre IVE (interrupción voluntaria del embarazo) ingresó a la agenda parlamentaria. Aunque el resultado fue el rechazo del proyecto (no fue aprobado sino hasta dos años más tarde, en 2020) mostró un escenario de movilización inédita en el sentido de la participación de diferentes actores de la sociedad civil producto de la decisión por parte del cuerpo legislativo de invitar a distintos actores sociales y políticos para que expresen su argumento frente al proyecto.

Esta exposición pública puede pensarse como materialización de la dimensión discursiva o ideológica que siguiendo a Fraser (2019) no se trata de algo diferente a las prácticas sino a "las normas tácitas y las suposiciones implícitas que constituyen dichas prácticas” (p. 198). Es decir, el debate parlamentario sobre aborto en Argentina organizó 
un espacio formal institucional para que la sociedad civil se manifestara públicamente en el que participaron una diversidad de actores. Esta diversidad es la que hizo del momento un escenario clave para desentramar los sentidos en disputa incluso por fuera del texto de la ley en sí. Porque las condiciones de publicidad no ignoran que los discursos esgrimidos en las reuniones plenarias legislativas no se limitan a quienes legislan, sino que expanden los límites de lo decible frente a audiencias mucho más amplias (por su eco en medios de comunicación masiva o en las movilizaciones callejeras, por nombrar algunos ejemplos en los que el espacio del debate se expande y adquiere publicidad).

La figura del aborto estaba regulada por el Código Penal Argentino desde 1921 y el debate del proyecto puso en evidencia precisamente este enmarque, la penalización. En las reuniones plenarias legislativas, quienes apoyaron el proyecto de legalización del aborto como los movimientos feministas utilizaron, estratégicamente o no, distintos argumentos basados en la salud pública, la mortalidad materna, la clandestinidad, la autonomía, el derecho al goce sexual, entre otros (Barrancos, 2018).

Estos significantes ya estaban instalados en el debate público- político por la acción persistente de los movimientos feministas. Sin embargo, como sostiene Levin (2018) con la instalación del conflicto político por el derecho al aborto en la agenda parlamentaria, los movimientos feministas impulsaron una transformación "en la sustancia de la democracia" así como en la praxis (p. 378). Esto es, despenalización implica que el aborto no se considere un delito que criminaliza a quienes deciden practicarlo y legalizar implica el reconocimiento de la práctica como un derecho garantizado por el Estado. Y esta transformación "tiene como horizonte consolidar nuevos derechos que desafían a las desigualdades y aportar más igualdad de género a la democracia” (Levin, 2018, p. 378).

Ahora bien, las manifestaciones públicas de oposición al proyecto iluminaron un aspecto importante vinculado especialmente con la figura de lo penal. Como dijimos, el dispositivo regulador del aborto estaba sujeto a las formas establecidas por el Código Penal (C.P.). Existían causales de no punibilidad tipificadas, pero en la práctica, incluso, éstas fueron sistemáticamente trabadas en particular por la judicialización de los casos (Ramón y Ariza, 2018).

Así, el crimen, la penalización, la punición como sentidos anquilosados en los sistemas judiciales, en la lógica víctima- victimario, en la tensión entre la individualización de las prácticas y el reconocimiento de un asunto como público, tomó cuerpo en un campo contradiscursivo donde una de sus manifestaciones fue y es su traducción en demandas por la ampliación de derechos llevadas adelante principalmente por movimientos feministas. El abrir los horizontes de sentido para construir otras formas no sólo politizándolos sino también frente al instituto de lo sancionado se convirtió en un campo de batallas en el que las plenarias legislativas por la legalización del aborto dejaron ver aquello que lo resiste movilizando recursos y estrategias en la búsqueda por mantener los marcos legales vigentes.

Una de las líneas de la batalla puede leerse en esta tensión. Si, por un lado, distintos actores y colectivos encaminaron sus esfuerzos para desplazar el aborto del ámbito punitivo, por el otro y del mismo modo, otros actores y colectivos buscaron defender e incluso reforzar la mirada punitivista (Sgró, 2020). 
Considerando la diversidad de actores que se manifestaron en contra del proyecto de ley (2018), es notable que la gran mayoría fueron presentados como profesionales especialistas vinculados con los ámbitos de la salud y lo jurídico (Sgró, 2020). Esto permite entrever que lo privilegiado por estos sectores fue anclar sus argumentos desde un lugar del saber. Un saber aferrado al poder de instituciones y academias cuyos modelos hegemónicos heteropatriarcales han sido recurrentes en la imposición de órdenes clasificatorios bajo la lógica víctima/victimario. Esto, además, no está ausente en los argumentos.

Si ponemos la mirada en profesionales del campo del derecho y la abogacía es visible que bajo distintas estrategias basadas en lo técnico del lenguaje jurídico (constitucionalidad, tratados de derechos humanos, entre otros ejes discursivos dominantes) o en contraposiciones interpretativas (por ejemplo, derecho a la vida/derecho al aborto) emerge lo punitivo como una dimensión clave. Vale recordar que estas exposiciones se producen en un escenario formal (plenarias legislativas) en un proceso de decisión para modificar o no el marco legal vigente. Pero lo excede dado que, si bien legisladores y legisladoras son la audiencia principal a la que se orientan (quienes detentan la responsabilidad de la votación y posterior sanción de la ley), los sentidos que ingresan al debate público no se limitan a esto. Al contrario, se expanden al público general. Puesto que quienes participan no desconocen esta condición, es válido pensar que también reconocen la politización del asunto y, por ello, no solo esgrimen argumentos, sino que los ubican en una disputa por los sentidos e interpretaciones en la que indefectiblemente se configura un otro.

Ese otro es delineado básicamente como quien viene a desordenar lo establecido no sólo a nivel del orden jurídico sino de los valores morales nacionales. Ese otro, aunque no tan mencionado, son en particular los movimientos feministas. La politización del aborto entonces demarca tanto una respuesta institucional al asunto (lo cual también implica su tratamiento legal) como cuestiones fuertemente vinculadas con la moralidad (Ramón, 2012). Por esta vía se puede agregar que frente a la legalización del aborto (la reconfiguración de horizontes interpretativos, la ampliación de derechos) los sectores opositores buscaron interpelar desde la tensión penalización/despenalización.

Si bien los argumentos para la legalización del aborto sostienen que no existen barreras jurídicas exponiendo una batería de fundamentos en esta línea (Levín, 2018; Ramón y Ariza, 2018) el rechazo buscó reafirmar la penalización y la figura del delito. Para ello, por ejemplo, consideraron la suficiencia de la regulación existente, especialmente, el $\mathrm{CP}$ como marco para dirimir situaciones conflictivas. Esto implica sostener la práctica del aborto como delito $y$, por ende, como sancionable basado también en otras interpretaciones jurídicas (por ejemplo, recurriendo al artículo 75 inc. 22 y 23 para fundamentar el derecho a la vida desde la concepción como derecho preexistente garantizado por la Constitución Nacional).

(...) Es precisamente debido a esa falta de autonomía, de su dependencia absoluta de la madre, de su total incapacidad de defenderse contra lo que ella pueda decidir en la más completa intimidad, que ese embrión, esa persona minúscula, necesita 
indefectiblemente del amparo de la ley penal, también frente a su madre (De la Riba, Ignacio, Dr. en Derecho, plenaria en Diputados, 17 de abril de 2018).

(...) a lo largo de toda la historia, y en los lugares más disímiles, se ha considerado al aborto como un delito. Como todo delito, comporta varias clases de males y consecuencias dañinas que la pena, en la medida de lo posible, intenta resolver (Schuff, Sebastián, Abogado, plenaria en Diputados, 1 de junio de 2018).

Mantener la sanción, la pena, el crimen. El orden justo deviene en este marco en la invisibilización implícita de las mujeres y personas gestantes. Las manifestaciones opositoras buscaron fortalecer incluso la criminalización como mecanismo pedagógico. Esto implica una necesidad para desalentar el aborto en la defensa institucional-legal de "niños no nacidos". Además, una conducta delictiva donde la pena y la sanción funcionarían como disuasorios, imprescindibles para combatir las prácticas "antijurídicas" y ordenar lo social como una de las funciones de la norma penal.

Estos sentidos emergen como fundantes de la negación del aborto como derecho y proponen una manera de ver lo justo desde la lógica víctima/victimario donde queda claro quién (qué sujeto) es el subordinado o negado (más allá de que explícitamente esto no sea reconocido sino al contrario, con el "salvemos las dos vidas" la cooptación del sentido de vida opera buscando desprenderse de este no-reconocimiento). Otra forma de desentramar lo que mencionamos antes, una "impunidad selectiva" (Arduino, 2018) la cual afirma al mismo tiempo que opaca todo un abanico de situaciones; por ejemplo, la clandestinidad. Además, se vigoriza: las manifestaciones públicas opositoras no se limitaron al mantenimiento de la penalización también avanzaron en denunciar la ineficacia del C.P. en la práctica y en la demanda por una mayor punición frente al aborto como delito. Si, por un lado, se trataba de fortalecer el aborto como crimen por otro lado también se buscó extender la punición vía el cuestionamiento al C.P., remarcando la necesidad de modificarlo para hacerlo incluso más restrictivo.

A la par de mantener la punición del delito de aborto, está a la vista la necesidad de modificar el artículo 86, estableciendo, como única excepción, la no punibilidad del aborto que se realiza con el fin de evitar un peligro para la vida o la salud de la madre, en tanto ese peligro no pueda ser evitado por otros medios (Alfredo Mario Condomí, Prof. de Derecho Penal, plenaria Diputados,18 de mayo de 2018).

Lo dicho hasta acá permite advertir cómo el derecho es un campo de disputas, pero también que estas controversias no necesariamente finalizan con la sanción de la ley. Sin dudas, el reconocimiento y la ampliación de DSyR es una necesidad en nuestras sociedades contemporáneas. Sin embargo, retomando a Fraser (2019), es central tanto la satisfacción como la interpretación de las necesidades "dado que toda satisfacción que podamos conseguir será problemática en el grado en que no logremos librar y ganar la batalla de la interpretación" (p. 218). Así, también se vuelve necesario que sea efectivo en la praxis al mismo tiempo que continuamente cuestionado. En particular, como dijimos antes, para sortear la confusión entre justicia formal y justicia social (Trebisacce, 2018). Continuamente cuestionado también porque la óptica neoliberal individualiza, responsabiliza por parir o no parir, culpa a escala personal "afantasma con palabras 
altisonantes como familia o vida, pero evitando la carne real de esas palabras, la existencia histórica que tienen, sus condiciones y posibilidades" (López, 2019, p.27). De ahí, la necesidad de construir justicia desde abajo, una justicia feminista que desborda lo institucional formal (sin desconocerlo) pero que está atenta frente a las rendijas de la justicia patriarcal.

\section{APORTES DESDE LOS FEMINISMOS COMUNITARIOS}

¿Cómo funciona una justicia institucional sin perspectiva de género(s), interseccional y feminista? Los feminismos comunitarios de Abya Yala sostienen que las personas y las comunidades sobrevivimos y vivimos aún a pesar del Estado y de sus mecanismos. Pues, como sostiene Segato (2007) nuestros Estados reproducen las lógicas patriarcales, coloniales y racistas. No obstante, es a los Estados a quienes les exigimos soluciones y órdenes de todo tipo, sin embargo, es la organización de las comunidades quienes -sobre todo en momentos críticos- sostienen respuestas urgentes y acciones colectivas. Como expresó Rita Segato, respecto del retorno de los feminismos a la calle:

"hay grandes debates entre el feminismo blanco institucional en América Latina que ha insistido en que la lucha feminista consiste en pasar leyes y tener un cuidado institucional para las mujeres ... fue importante pero no ha mostrado una capacidad ... para hacer retroceder el feminicidio por ejemplo, entonces hay un agotamiento en ese camino, el camino blanco ... institucional, luego está surgiendo el feminismo comunitario, el feminismo indígena, el feminismo negro, no solo hay que aprender de la mujer indígena y negra que habla en nuestros continentes, la vanguardia ... está con ellas, pero también preservarnos de una influencia corrosiva colonial al interior del propio movimiento social" (CLACSO TV, 2018, 9m50s).

En este marco, la Justicia, en nuestra región latinoamericana, no está por fuera de la expresión y lengua colonizadora que oculta las pluralidades de realidades que existen en nuestros territorios. Los casos denunciados en la Sentencia del Tribunal Ético Popular Feminista (2018), son una expresión de las características universalizantes, androcéntricas, patriarcales, y racistas de los sistemas de justicia. Lo que se manifiestó en las audiencias llevadas a cabo en distintas localidades, ciudades y países: en Argentina en Chaco, CABA, Rosario, Guernica -en Provincia de Buenos Aires- y en Lago Puelo -en Chubut-; en Uruguay en la ciudad de Montevideo y en Paraguay en la capital de Asunción (Korol, 2019).

En Guatemala frente a la criminalización de defensoras de territorios y tierra y feminicidios territoriales, políticos y de Estado (Sentencia del Tribunal Ético Popular Feminista, 2018) son los feminismos comunitarios quienes sostienen que la justicia sea construida colectivamente no solamente como herramienta sancionatoria sino también sanadora. Consideran que el derecho estatal es represivo, punitivo, castigador, esquemático, burocrático y, en algunos casos, vengativo (Cumes, 2009). Por el contrario, una manera de resistir es recurrir a la memoria ancestral como una estrategia de sanación emocional y espiritual que permite recuperar las voces de las mujeres y sujetos plurales feminizados como una acción que representa una justicia simbólica "que permite que ellas se empoderen y luchen por el acceso a la justicia” (Ruiz Tena, 2020, p.14). La recurrencia 
a la memoria ancestral, así como la apuesta por la comunidad, es denominado como "sanación como camino cósmico-político" (Cabnal, 2019, p.123).

En consecuencia, los feminismos indígenas tienen sus propias críticas al sistema judicial colonial que tenemos en Nuestra América. Cumes (2009) señala que lo que sucede en las comunidades mayas (y en otros territorios indígenas) es que el derecho colonial encarcela a los varones violentos, pero estos mecanismos de exclusión no son validados comunitariamente: "por lo regular la mujer prefiere dejarlo así, porque al encarcelar al esposo se afecta a los propios hijos y a la esposa” (Cumes, 2009, p.17). Entonces, se opta por el sistema jurídico indígena compuesto por personas de su propia comunidad quienes, además, han realizado trabajos comunitarios, se han comportado ejemplarmente y tienen ciertos méritos personales (Cumes, 2009); focalizando en la defensa del respeto a la vida e inmiscuyéndose en lo cotidiano de la comunidad pues "el derecho no puede ser un ente puro ni separado de lo que ocurre en la comunidad" (Cumes, 2009, p.18).

Por su parte, desde los feminismos de Abya Yala se hace una crítica al sistema que precariza la vida y se apuesta por un feminismocomunitario -sí, así, todo junto- pues sostienen que la comunidad no puede desligarse de los feminismos. Desde Bolivia, Guzmán (2019) apunta a la unión de género(s) "con relación a la comunidad, denunciando y luchando contra el machismo y el patriarcado (...) una comunidad que no parte de los derechos, sino del respeto y responsabilidad con la vida" (p.31).

¿Cómo se acciona? A partir de metodologías participativas, donde la toma de la palabra comprendida como recurso y potencia entre quienes han tenido negadas sus voces: "encontrarse, desencontrarse e inventar, todo eso y más es el tejido, el movimiento de la comunidad" (Guzmán, 2019, p.54). Compartir espacios de reflexión, transformación y también de autocrítica en las formas de organizar las microestructuras sociales y las justicias feministas y populares. Para ello debemos considerar que debe eliminarse la precarización de la vida y reconstruir el tejido social comunitario no sólo para prevenir violencias machistas y crear condiciones dignas de vida sino también para actuar frente a estas.

\section{A MODO DE CIERRE}

No podemos dejar de concebir el sistema estatal de justicia, enmarcado y sujeto a diferentes críticas: la falta de legitimación, la que se revela en la desconfianza desde la ciudadanía respecto de la administración de justicia, sostenida en general en la selectividad del sistema penal, limitaciones en el acceso a la justicia y en las demandas de democratización de los poderes judiciales (Bergoglio, 2010). Esto implica incrementar mecanismos reales de participación que permita canales, comunicaciones y espacios no solo para acceder a la protección estatal sino también para crear otras formas de comprender, hacer y disputar sentidos de derechos y justicias.

Guzmán (2019) desde el feminismo comunitario de Bolivia plantea la autoorganización y autogobierno frente a las lógicas patriarcales, coloniales y racistas. Esto no implica dejar de lado exigencias hacia el Estado y la construcción de nuevos ordenamientos jurídicos (como fue la Constitución Plurinacional en su momento), sin embargo, es la comunidad en tanto que agencia central de los cambios sociales, la que 
interpela al Estado por medio de la organización y sostenimiento desde las redes de solidaridad, intercambios y luchas.

Las audiencias del Tribunales Éticos Feminista de Abya Yala no solo se dirige al Estado y lo interpela, también plantea una idea de justicia frente a lo que llaman Justicia con letra mayúscula; es decir, si bien se construyen desde la subaltenización que produce la modernidad binaria, también hablan desde sus propias experiencias y situaciones como sobre otra justicia para pensarse por fuera de la estructura del uno, es decir de la esfera pública "que totaliza, secuestra y monopoliza toda la política" (Segato, 2012, p. 4). Como tal, la justicia en clave feminista y comunitaria puede pensarse en el intersticio de lo subalterno-binario frente al Estado; cuestiona la Justicia frente a su accionar sobre las mujeres y disidencias; propone la construcción de lo plural como formas de ser otro (alteridades históricas) al hablar por sí mismas y pensar otro tipo de justicia que problematiza la estructura clasista, patriarcal, colonial y heterosexual de la Justicia estatal. Como indica López (2020) “[...] hacer política anticapitalista va más en el sentido de una invención de otras formas de vida que en el de activación de medidas judiciales, aunque sean centrales para que los derechos no sean avasallados" (p.1). Urge la necesidad de construir una justicia que desborda lo estatal -pero reconoce a su vez su importancia en la ampliación y sostenimiento de derechos-, es decir, cuestiona, interpela, visibiliza, al mismo tiempo que promueve otras formas e imaginaciones de justicias.

La apuesta por formas de justicia feminista apunta, ante todo, a recuperar la politicidad cancelada y a hallar maneras que resten punitivismo (que, como vimos es uno de los lenguajes privilegiados por los conservadurismos) y que sumen soluciones a las realidades por las que atravesamos desde una construcción comunitaria y antipatriarcal. Así, las imaginaciones feministas se ponen en movimiento para seguir generando cambios culturales y alterar las miradas colonizadoras y racistas. Las apuestas pasan por devolver los conflictos a la comunidad de manera de generar respuestas nuevas, de senti-pensar nuestras afectividades y vínculos frente a las violencias patriarcales.

\section{REFERENCIAS BIBLIOGRÁFICAS}

Aramayo, S., Caletti, P., Coliqueo, A., de la Torre, N., Herrera, M.,Nievas Ibáñez, P., Lande, C. y Noccioli, A. (2021). Documento de posicionamiento sobre bases para una reforma judicial feminista: de qué hablamos cuando nos referimos a la reforma judicial feminista. Revista Movimiento, (32), 6-21. https://www.revistamo vimiento.com/wp-content/uploads/2021/05/Movimiento-32.pdf

Arduino, I. (2018). Entre la victimización opresiva y la justicia emancipadora: Articulaciones entre feminismo y justicia penal. En M. Nijensohn (Ed.), Los feminismos ante el neoliberalismo (pp. 51-62). La Cebra.

Ariza, S.; Saldivia, L. (2015). Matrimonio igualitario e identidad de género sí, aborto no.

Derecho y Crítica Social, 1 (1), 181-209. https://doi.org/10.1590/1984-6487.sess.2016. 22.02.a

Arnés, L. A. (27 de abril de 2017). "Si tocan a una nos tocan a todas": Sobre feminismos, violencia machista y punitivismo". Filo Debate. http://investigacion.filo.uba.ar/ sites/investigacion.filo.uba.ar/fi-les/u6/Filo\%20Debate_Arnes.pdf 
Azcue, L. y Ardusso S. (7 de abril de 2021). ¿Será Justicia? Reforma Judicial. Página 12. https://www.pagina12.com.ar/127775-no-mas-ceguerahttps://www.pagina12. com.ar/334141-reforma-judicial-feminista

Barrancos, D. (2018). La ley abortada: Notas sobre el debate de la interrupción voluntaria del embarazo. Salud Colectiva, 14 (3) 373-376.https://doi.org/10.18294/sc. 2018.2025

Barrancos, D. (2019). La arqueóloga de la historia feminista. Crónica de Cintia Kemelmajer. Revista Anfibia. (http://revistaanfibia.com/cronica/la-arqueologade-la-historia-feminista/).

Bergoglio, M. I. (2010). Subiendo al estrado: La experiencia cordobesa de juicio por jurados. Advocatus.

Brown, J. (2017). El aborto en el Congreso Nacional. Los proyectos del activismo conservador religioso en diputados (Argentina, 2004-2014). Descentrada. Revista Interdisciplinaria de feminismos y género, 1 (2), 1-16. http:/ /www.memoria.fahce. unlp.edu.ar/art_revistas/pr.7914/pr.7914.pdf

Cabnal, L. (2019). El relato de las violencias desde mi territorio cuerpo-tierra. En Leyva Solano, X.; Icaza, R. (Ed.), En tiempos de muerte: cuerpos, rebeldías, resistencias (Vol. IV). Cooperativa Editorial Retos, CLACSO. https://www.clacso.org.ar/ libreria-latinoamericana/buscar_libro_detalle.php?id_libro $=1759 \&$ campo $=$ autor\& texto $=$

Cano, V. (6-8 de abril de 2016). Crítica de la razón femicida: sexualidad, amor y poder. [Discurso principal]. III Jornadas Sexualidades Doctas. Facultad de Filosofía y Humanidades, Universida Nacional de Córdoba (UNC), Córdoba, Argentina.

Cano, V. (2020). Afecciones punitivas e imaginación política: des-bordes de la lengua penal.

En D. Daich y C. Varela, C. (Ed.), Los feminismos en la encrucijada del punitivismo (pp.75-90). Editorial Biblos.

CLACSO TV. (2018). Rita Segato en Espacio de Formación Virtual CLACSO. [Archivo de Vídeo]. Youtube.https://www.youtube.com/watch?v=WUjDAgKFwME

Cumes, A. (2009). Sufrimos vergüenza: mujeres k'iche' frente a la justicia comunitaria en Guatemala. Desacatos, (31), 99-114.http://www.scielo.org.mx/pdf/desacatos/ n31/n31a7.pdf

Daich, D., \& Varela, C. (2020). Los feminismos en la encrucijada del punitivismo. Editorial Biblos.

Deangeli, M.; Gastiazoro, M.E. y Sánchez, M. (2019). El ideal modélico de mujer-madre en la construcción del imaginario social del estado moderno en Argentina. Revista de la Facultad de Derecho y Ciencias Políticas, UNSAAC, 4(11), 65-87. http://revistas.unsaac.edu.pe/index.php/RFDCP/article/view/135/110

Drovetta, R. (2015). Líneas telefónicas de información sobre aborto seguro: una estrategia efectiva para incrementar el acceso de las mujeres a los abortos seguros en América 
Latina. Reproductive Health Matters, 23(45), 47-57. https://doi.org/10.1016/ j.rhm.2015.06.004

Fraser, N. (2019). Prácticas rebeldes. Poder, discurso y género en la política social contemporánea. Prometeo.

Guzmán, A. (2019). Hay un feminismo racista, colonialista y eurocéntrico. Exposición en el Ciclo de Feminismos Populares. Senda Guevarista. (https://sendaguevarista. org/2019/09/26/adriana-guzman-hay-un-feminismo-racista-colonialista-y-euroce ntrico/)

Guzmán, A. (2019). Descolonizar la Memoria, Descolonizar los Feminismos. Ed. Tarpuna Muya.

Korol, C. (11 de julio de 2018). No más ceguera. Página 12. https://www.pagina12.com. ar/127775-no-mas-ceguera

Korol, C. (2019). Juicio a la justicia patriarcal. Hacia una justicia feminista, antirracista, originaria, comunitaria y popular. En A. Moreno; D. Maffía; P. L. Gómez, (Ed.), Miradas feministas sobre derechos (pp. 49-64). Editorial Jusbaires. http://editorial.jusbaires.gob.ar/libros/250/online

LATFEM (26 de mayo de 2021). ¿De qué hablamos cuando decimos reforma judicial transfeminista? LATFEM. https://latfem.org/de-que-hablamos-cuando-decimosreforma-judicial-transfeminista/

Lerussi, R. C. y Costa, M. (2018). Los feminismos jurídicos en Argentina. Notas para pensar un campo emergente a partir de la década de 1990. Revista Estudos Feministas, 26 (1), 1-13. https://doi.org/10.1590/\%25x

Levin, S. (2018). ¿Salud sexual y salud reproductiva sin libertad? El conflicto por el aborto en Argentina. Salud Colectiva, 14(3), 377-389. https://doi.org/10.18294/ sc. 2018.2011

López, M.P (2019). Apuntes para las militancias: feminismos: promesas y combates. Estructura Mental a las Estrellas.

López, M. P. (2020). Vida, justicia y deseo. Ideas. Revista de filosofía moderna y contemporánea, (11), 76-80. http://revistaideas.com.ar/wp-content/uploads/ 2020/06/dossier-feminismos-1.pdf.

Pitch, T. (2014). La violencia contra las mujeres y sus usos políticos. Anales de la Cátedra Francisco Suárez, (48), 19-29. https://revistaseug.ugr.es/index.php/acfs/article/ view $/ 2778 / 2895$

Ramón Michel, A.; Ariza, S. (2018). La legalidad del aborto en la Argentina. No 9 - Serie de documentos. REDAAS. http://www.redaas.org.ar/nuestro-trabajodocumento.php?a=129.

Ramón Michel, A. (2012). Aborto: ¿según quién? En J. Morán Faúndes, C. Sgró Ruata y J. Vaggione (Ed.), Sexualidades, Desigualdades y Derechos: Reflexiones en torno a los derechos sexuales y reproductivos (pp. 275-336). Ciencia, Derecho y Sociedad. 
https://programaddssrr.files.wordpress.com/2013/05/sexualidades-desigualdade s-y-derechos.pdf

Ruiz Tena, C. (Ed.) (2020). Tejiendo Mujeres Trenzando luchas. Los obstáculos de la participación. Política de la diversidad de mujeres en Guatemala. Sisa- Mujeres Activando: Ed. Asuntos del Sur. https://asuntosdelsur.org/wp-content/uploads/ 2020/06/tejiendo_mujeres_interior_interactivo.pdf

Salvatore, R. (2010). Subalternos, derechos y justicia social. Ensayos de historia social y cultural argentina 1829-1940. Gedisa.

Santin, M. A. V.; Cattani, D.; Cechetti, E. (2019). Gênero e religião: disputas políticas na construção do plano municipal de educação de Chapecó/sc. Revista Pedagógica, (21), 306-320. https://doi.org/10.22196/rp.v22i0.5261

Santos, B. de S. (2009). Sociología jurídica crítica. Para un nuevo sentido común en el derecho. Trotta/ILSA.

Segato, R. L. (2007). El color de la cárcel en América Latina. Apuntes sobre la colonialidad de la justicia en un continente en deconstrucción. Nueva Sociedad, (208), 142161. http://www.casi.com.ar/sites/default/ files/El $\% 20$ color $\% 20 \mathrm{de} \% 201 \mathrm{a} \% 20 \mathrm{c} \% 23 \mathrm{U}$ $00 \mathrm{e} 1 \mathrm{rcel} \% 20 \mathrm{en} \% 20 \mathrm{Am} \% 23 \mathrm{U} 00 \mathrm{e} 9 \mathrm{rica} \% 20 \mathrm{Latina}$.pdf

Segato, R. L. (2012). La Lengua Subalterna. Entrevista por GAGO, Verónica. Ciclo organizado por Lectura Mundi en la Universidad Nacional de San Martín, Argentina. https://www.academia.edu/12050743/La_Lengua_Subalterna_ entrevista_a_Ver\%C3\%B3nica_Gago_gentil_transcripci\%C3\%B3n_de_Maura_B righenti_y_Santiago_Sburlatti_

Sentencia del Tribunal Ético Popular Feminista (30 de junio de 2018). Buenos Aires. https://www.biodiversidadla.org/Documentos/Sentencia_del_Tribunal_Etico_F eminista._Juicio_a_la_Justicia_Patriarcal

Sgró Ruata, M. C. y Gastiazoro, M. E. (2018). Educación sexual como clivaje del debate parlamentario por la legalización del aborto en Argentina. Momento - Diálogos Em Educação, 27(3), 65-84. https://doi.org/10.14295/momento.v27i3.8326

Sgró Ruata, M. C. (2020). Configuraciones conservadoras: actores y discursos de oposición en la política sexual argentina (Informe de investigación). CONICET, Argentina [s.n].

Smart, C. (2000). La teoría feminista y el discurso jurídico. En H. Birgin (Ed.), El derecho en el género y el género en el derecho (pp. 31-71). Biblós.

Trebisacce, C. (2016). Una historia crítica del concepto de experiencia de la epistemología feminista. Cinta de Moebio, (57), 285-295. http://dx.doi.org/10.4067/S0717554X 2016000300004

Trebisacce, C. (2018). Habitar el desacuerdo. Notas (nunca urgentes) para un elogio de la precariedad política. Mora, (24), 185-190. https://doi.org/10.34096/mora.n24. 6317 
Urizar, L. (2000). El derecho consuetudinario en el contexto de las relaciones de género. En J. Solares (Ed.), Pluralidad jurídica en el umbral del siglo. FLACSO.

Vasallo, J. (2007). Castas, honestas, viles y malas. La mujer en el imaginario jurídico de la América colonial. Anuario X, Centro de Investigaciones Jurídicas y Sociales, (10), 493-505. https:// cijs.derecho.unc.edu.ar/2018/12/16/anuario-x/

Viveros Vigoya, M. V. (2016). La interseccionalidad: una aproximación situada a la dominación. Debate feminista, 52,1-17. https://doi.org/https://doi.org/10.1016/ j.df.2016.09.005

\section{CITAR COMO:}

Gastiazoro, M. E., Sgró Ruata, C., \& Bonavitta, P. (2021). Justicia en clave feminista y comunitaria: des(bordes) frente a las institucionalidades patriarcales. Puriq, 3(4), 555-570. https://doi.org/10.37073/puriq.3.4.232 